\title{
Evaluation of the orthodontic treatment need in a paediatric sample from Southern Italy and its importance among paediatricians for improving oral health in pediatric dentistry
}

\author{
Valeria Luzzi ${ }^{1}$, Gaetano Ierardo ${ }^{1}$, Denise Corridore ${ }^{1}$, Gabriele Di Carlo ${ }^{\text {, }}$ Gianni Di Giorgio ${ }^{1}$, Emanuele \\ Leonardi $^{2}$, Guglielmo-Giuseppe Campus ${ }^{3,4}$, Iole Vozza ${ }^{1}$, Antonella Polimeni ${ }^{1}$, Maurizio Bossù ${ }^{1}$
}

${ }^{1}$ Department of Oral and Maxillofacial Sciences, "Sapienza” University of Rome, Rome, Italy

${ }^{2}$ Istituto Nazionale di Fisica Nucleare (INFN), Sezione di Roma, Rome, Italy

${ }^{3}$ School of Dentistry, University of Sassari, Italy

${ }^{4}$ WHO Collaborating Centre for Epidemiology and Community Dentistry of Milan, University of Milan, Italy

Correspondence:

Department of Oral and Maxillofacial Sciences

"Sapienza" University of Rome

Via Caserta 6 - 00161 Rome, Italy

valeria.luzzi@uniroma1.it

\begin{abstract}
Luzzi V, Ierardo G, Corridore D, Di Carlo G, Di Giorgio G, Leonardi E, Campus GG, Vozza I, Polimeni A, Bossù M. Evaluation of the orthodontic treatment need in a paediatric sample from Southern Italy and its importance among paediatricians for improving oral health in pediatric dentistry. J Clin Exp Dent. 2017;9(8):e995-1001.

http://www.medicinaoral.com/odo/volumenes/v9i8/jcedv9i8p995.pdf
\end{abstract}

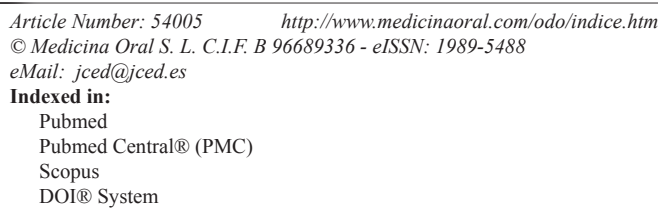

\begin{abstract}
Background: Data from epidemiological studies investigating the prevalence and severity of malocclusions in children are of great relevance to public health programs aimed at orthodontic prevention. Previous epidemiological studies focused mainly on the adolescence age group and reported a prevalence of malocclusion with a high variability, going from $32 \%$ to $93 \%$. Aim of our study was to assess the need for orthodontic treatment in a paediatric sample from Southern Italy in order to improve awareness among paediatricians about oral health preventive strategies in pediatric dentistry .

Material and Methods: The study used the IOTN-DHC index to evaluate the need for orthodontic treatment for several malocclusions (overjet, reverse overjet, overbite, openbite, crossbite) in a sample of 579 children in the 2-9 years age range.

Results: The most frequently altered occlusal parameter was the overbite (prevalence: $24.5 \%$ ), while the occlusal anomaly that most frequently presented a need for orthodontic treatment was the crossbite $(8.8 \%)$. The overall prevalence of need for orthodontic treatment was of $19.3 \%$, while $49 \%$ of the sample showed one or more altered occlusal parameters. No statistically significant difference was found between males and females.

Conclusions: Results from this study support the idea that the establishment of a malocclusion is a gradual process starting at an early age. Effective orthodontic prevention programs should therefore include preschool children being aware paediatricians of the importance of early first dental visit.
\end{abstract}

Key words: Orthodontic treatment, malocclusion, oral health, pediatric dentistry. 


\section{Introduction}

Data from epidemiological studies investigating the prevalence and severity of malocclusions in children are of great relevance to the implementation of public health programs aimed at orthodontic prevention. In this context epidemiology becomes a useful tool for the early diagnosis of malocclusions, contributing to the limitation of further aggravations of the same during the later stages of growth (1-4).

In order to evaluate the prevalence of malocclusions and the associated risk factors, several measurement indexes were defined over the years. Early examples are the Grainger's "Treatment Priority Index" (TPI) (5), the Salzmann's "Handicapping Malocclusion Assessment Record" (6) or the Summers' "Occlusal Index" (7). In 1989 Brook and Shaw defined the "Index of Orthodontic Treatment Need" (IONT) with the associated "Peer Assessment" (8). This index, with the following modifications by Shaw (9), is now widely used in the clinical practice.

Epidemiological studies on the prevalence of malocclusions and on the need of orthodontic treatment (10) conducted in several countries reported a prevalence of malocclusion with a high variability, going from $32 \%$ to 93\% (11-14). This inhomogeneity can be attributed to several factors: the use of different indexes, including IOTN and TPI (with several modifications), the different age, social status, and ethnic group of the samples studied, and the data collection techniques.

Aim of our study was to assess the need for orthodontic treatment in a paediatric sample from a well-defined geographical area of Southern Italy, namely the Caserta province in order to improve awareness among paediatricians about oral health preventive strategies in pediatric dentistry .While most studies in the literature focused on the adolescent age range $(14,15)$, our study focused on the 2-9 years age group, this in order to evaluate the prevalence of malocclusions and need for treatment at an earlier age and to intercept as early as possible in childhood the clinical evolution of the malocclusion and consequently implement proper treatment protocols to prevent its aggravation.

\section{Material and Methods}

579 children (2-9 years old) were examined in collaboration with paediatricians from the Caserta province (Italy), in the period between June 2009 and June 2010, as part of a large epidemiological study designed to establish a whole set of risk factors related to oral health.

The study protocol was conformed to the ethical guidelines of the 1975 Declaration of Helsinki and was approved by the Ethics Committee of the Policlinico "Umberto I" in Rome and the authorization to the clinical examination of the children and to the processing of the personal data has been obtained by written informed consent signed by both parents.
-Sample selection

Caserta is a southern Italian city located in the north of the Campania region. The province of Caserta and its metropolitan area have a population of about 910,000 inhabitants ${ }^{\mathrm{a}}$.

45 paediatricians working in the province of Caserta and belonging to the Italian Society of Preventive and Social Paediatrics ${ }^{\mathrm{b}}$ (SIPPS) participated to the project. According to the italian system, each child born in the province of Caserta is randomly assigned to a pediatrician belonging to the Public Health Service, of which SIPPS is a good proxy. Thus the set of children covered by SIPPS provide a representative approximation of the population in the area.

Each paediatrician recruited, on a voluntary base, a random sample of 10 to 20 children in the required age range for a routine dental check. An exclusion criterion from the study was the existence of a previous or ongoing orthodontic treatment.

All patients were examined using a mirror, a disposable explorer, and a metal gauge. The children were sitting on the examination table and examiners used a portable $60 \mathrm{~W}$ white lamp as light source.

${ }^{a}$ Data from ISTAT $2001-14^{\circ}$ Censimento Generale della Popolazione e delle Abitazioni. Available on-line at http://dawinci.istat.it

${ }^{\mathrm{b}}$ Società Italiana di Pediatria Preventiva e Sociale. Web site: http://www.sipps.it

An initial physical examination collected the family, physiological, and pathological medical histories of each subject into a medical file specifically created for the study, while the parents were required to fill a questionnaire related to non-nutritive sucking habits (use of pacifier and finger sucking) of the child from the first to sixth year of life.

Data collected for this study included information related to caries experience and its associated risk factors: this section of the study was already presented in a previous publication (16).

-Orthodontic parameters

On examination, the orthodontic parameters for overjet, reverse overjet, overbite, anterior openbite, and posterior mono- or bi-lateral crossbite were measured using the following criteria:

- Overjet (OVJ) - Projection of the upper central incisor on the lower one along the sagittal plane. Using a metal gauge we measured the distance between the buccal surface of the lower central incisor and the palatal surface of the upper central incisor along the parallel to the occlusal plane.

-Reverse overjet (OVJ-) - The lingual surface of the lower central incisor is positioned anterior to the buccal surface of the upper incisors. We measured the distance between the buccal surface of the upper incisors and the lingual surface of the lower incisors along the parallel to the occlusal plane. 
-Overbite (OVB) - This is the overlap in the vertical plane of the upper teeth on the lower ones. The metal gauge was positioned perpendicularly to the occlusal plane and measured the section of the labial surface of the lower incisors covered by the palatal surface of the upper incisors, in the presence of rear dental contact.

-Anterior openbite (OPB) - When the upper central incisors were not in contact with the lower ones along the vertical plane, we measured the width of the resulting gap perpendicularly to the occlusal plane.

- Crossbite (CRB) - In a posterior cross-bite the buccal cusps of the upper deciduous molars and of the upper first permanent molar occlude lingually to the buccal cusps of the corresponding lower elements. Given to age range of the children, it was not possible to measure the entity of the dental discrepancy but only to identify its presence and characterize it as mono- or bi-lateral.

To reduce inter-examiner error, the same dental team carried out all visits. All members of the team underwent a preliminary calibration session to guarantee an unambiguous identification of the malocclusions and a coherent evaluation of the relevant occlusal parameters.

Using the measured parameters, we assigned a grade to the need for orthodontic treatment of each malocclusion following the IOTN-DHC (Index of Orthodontic Treatment Need - Dental Health Component) classification, detailed in Table 1. Given operative constraints related to the age of the children and to the time available for the exam, some of the criteria listed in table 1 were modified as follow:

- CRB was only reported as "present" or "absent" and, if present, it was classified as of grade 4 (i.e. to be treated).

- In presence of OVJ-, it was not possible to reliably evaluate the presence of speech and/or masticatory difficulties. This implied that it was not possible to identify grade 5 anomalies and that some of the grade 4 anomalies were classified as grade 3 .

In view of these limitations, all malocclusions were then classified as "altered" if the IOTN-DHC grade was $\geq 2$ and "to be treated" if the IOTN-DHC grade was $\geq 3$. This choice was taken in agreement with a Swedish study of 2009 stating that IOTN-DHC grade 3 anomalies should be included in the orthodontic treatment need (17).

Finally, we assigned to each subject an overall IOTNDHC grade, defined as the grade corresponding to the severest occlusal anomaly.

-Statistical methods

Prevalence was evaluated using the Wilson method with a $95 \%$ confidence interval.

The chi-square test of Pearson was used to compare the orthodontic treatment need in both sexes. A $p$ value $<0.05$ was considered statistically significant.

All calculations were performed using the SPSS 13.0 software (SPSS Inc., Chicago, Illinois) and the CIA Software 2.0.

\section{Results}

The sample included a total of 579 children (306 males and 273 female) ranging in age from 2 to 9 years (mean age 5.73, median 6, SD 1.65). Almost all children were of Italian nationality (99.3\%). Due to lack of compliance during orthodontic examination, in 20 subjects it was not possible to reliably measure the IOTN-DHC. These subjects were therefore excluded from the study.

For each malocclusion and for the overall need for orthodontic treatment we evaluated the distribution of IOTN-DHC grade both in the full sample and in the males and females sub-samples. Using the Wilson method we then evaluated the prevalence of each malocclusion in terms of the presence of an alteration (sum of IOTNDHC grades from 2 to 5) and in terms of the need for treatment (sum of IOTN-DHC grades from 3 to 5). Finally, we used the chi-square test to assess the likelihood that this prevalence is different between males and females. The results for each malocclusion (OVJ, OVJ-, OVB, OPB, and CRB) together with the overall IOTNDHC grade are summarized in table 2.

From these results we observe that the most frequently altered occlusal parameter is the overbite (prevalence: 24.5\%, 95\% C.I.: (21.1-28.3)\%) followed by overjet (20.6\%, (17.5-24.1)\%), openbite (11.4\%, (9.1-14.3)\%), crossbite $(8.8 \%,(6.6-11.4) \%)$ and reverse overjet $(2.5 \%$, (1.5-4.1)\%), as shown in Figure 1, with an overall prevalence of $49.0 \%$ and a $95 \%$ C.I. of (44.9-53.1)\%.

On the other hand, the occlusal anomaly that most frequently presents a need for orthodontic treatment is the crossbite (prevalence: $8.8 \%$, 95\% C.I.: (6.6-11.4)\%) followed by openbite $(5.7 \%,(4.1-7.9) \%)$, overbite $(4.3 \%$, $(2.9-6.3) \%)$, overjet $(2.3 \%,(1.4-4.0) \%)$ and reverse overjet $(0.5 \%,(0.2-1.6) \%)$, as shown in Figure 2, with an overall prevalence of $19.3 \%$ and a $95 \%$ C.I. of (16.2$22.8) \%$.

None of the malocclusions presented a statistically significant difference between males and females.

\section{Discussion}

The primary objective of this study was to analyse the need for orthodontic treatment in a paediatric sample from the Caserta province in order to acquire elements for the implementation of Public Health protocols related to malocclusions prevention. The need for orthodontic treatment was evaluated using the IOTN-DHC index.

We observed the highest prevalence of need for orthodontic treatment for the crossbite $(9.0 \pm 2.4 \%)$ followed by openbite $(6.0 \pm 1.9 \%)$. These data are in agreement with those reported in the literature, which always identified the crossbite as having a priority in the need for treatment since the early childhood (18-20).

When evaluating the results for the overall IONT-DHC grade, we note that two earlier studies used this method to examine paediatric populations of Southern Italy. In 
Table 1: IOTN-DHC classification for the treatment need of orthodontic malocclusions.

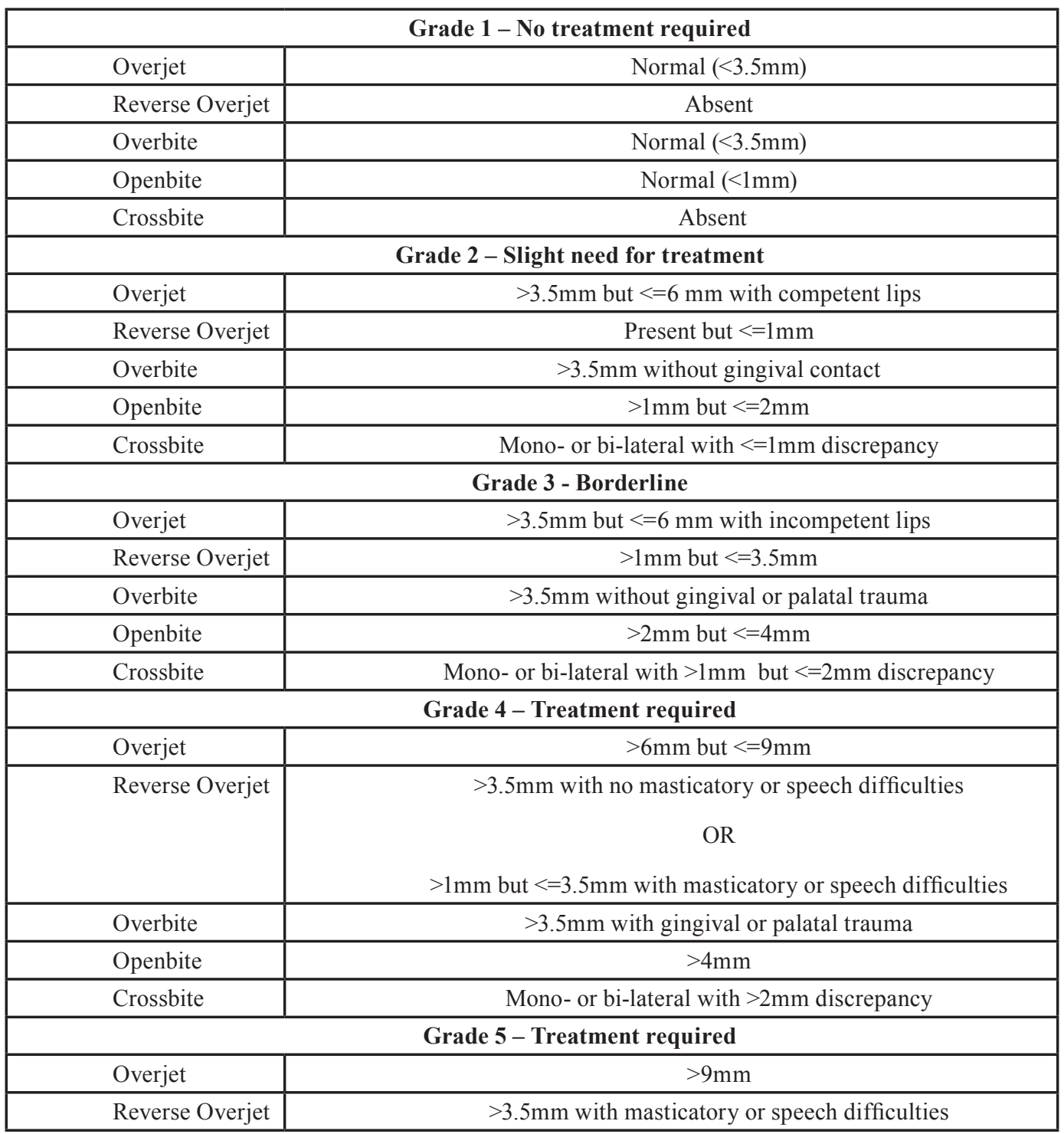

2007, Nobile et al. (21) studied a sample of children in the 11-15 years age range from middle and high schools of Catanzaro and found a high prevalence of malocclusion: approximately $59.5 \%$ of the sample required orthodontic treatment of 4th and 5th grade IONT. In 2009 another study (22) analysed a sample of 703 12-yearold children from several junior high schools in Naples, and found that $27.3 \%$ of the sample required orthodontic treatment of 4 th and 5 th IONT-DHC grade. The first French study using the IONT dates back to 2006: it examined 511 children in the 9-12 years age range and reported a prevalence of $21.3 \%$ of orthodontic treatment need (23). This finding agrees with a Spanish study of 2009 reporting a need for treatment equal to $21.8 \%$ in a group of 12-year-old children (24). This prevalence is comparable to that found in other studies that used the
IONT index8, (25-28), but lower than that observed, for example, in Africa $(29,30)$ or in Turkey $(31)$, and Jordan (32) in which the prevalence of malocclusion that definitely needs a treatment varies between $34 \%$ and $83.2 \%$. Our research shows that the prevalence of children who definitely need an orthodontic treatment plan (IOTNDHC grades 4 and 5) is of $11.1 \%$ and rises to $19.3 \%$ if we include grade 3 . These figures are lower than the cited studies: this is probably due to the fact our sample was aged between 2 and 9 years, i.e. lower than the average of other studies. On the other hand our analysis shows that about $49 \%$ of children present at least one occlusal anomaly. This figure, combined with the above considerations on the need for treatment, indicates that the establishment of a malocclusion is a gradual process starting at an early age. Any effec- 
Table 2: Prevalence of the IOTN-DHC grade for Overjet (OVJ), Reverse Overjet (OVJ-), Overbite (OVB), Openbite (OPB), Crossbite (CRB) and for the overall need for treatment. A comparison between male and female subjects is also shown.

\begin{tabular}{|c|c|c|c|c|c|c|c|c|}
\hline \multicolumn{9}{|c|}{ Overjet (OVJ) } \\
\hline IONT-DHC Grade & \multicolumn{2}{|c|}{ Prevalence } & $95 \%$ C.I. & \multicolumn{2}{|c|}{ Male } & \multicolumn{2}{|c|}{ Female } & $p$ \\
\hline Grade 1 & 444 & $79.4 \%$ & & 242 & $81.2 \%$ & 202 & $77.4 \%$ & \\
\hline Grade 2 & 102 & $18.2 \%$ & & 48 & $16.1 \%$ & 54 & $20.7 \%$ & \\
\hline Grade 3 & 10 & $1.8 \%$ & & 5 & $1.7 \%$ & 5 & $1.9 \%$ & \\
\hline Grade 4 & 2 & $0.4 \%$ & & 2 & $0.7 \%$ & 0 & $0.0 \%$ & \\
\hline Grade 5 & 1 & $0.2 \%$ & & 1 & $0.3 \%$ & 0 & $0.0 \%$ & \\
\hline Altered (Gr.2-5) & 115 & $20.6 \%$ & $(17.5-24.1) \%$ & 56 & $18.8 \%$ & 59 & $22.6 \%$ & 0.266 \\
\hline To treat (Gr.3-5) & 13 & $2.3 \%$ & $(1.4-4.0) \%$ & 8 & $2.7 \%$ & 5 & $1.9 \%$ & 0.547 \\
\hline \multicolumn{9}{|c|}{ Reverse Overjet (OVJ-) } \\
\hline IONT-DHC Grade & \multicolumn{2}{|c|}{ Prevalence } & $95 \%$ C.I. & \multicolumn{2}{|c|}{ Male } & \multicolumn{2}{|c|}{ Female } & $p$ \\
\hline Grade 1 & 545 & $97.5 \%$ & & 292 & $98.0 \%$ & 253 & $96.9 \%$ & \\
\hline Grade 2 & 11 & $2.0 \%$ & & 5 & $1.7 \%$ & 6 & $2.3 \%$ & \\
\hline Grade 3 & 3 & $0.5 \%$ & & 1 & $0.3 \%$ & 2 & $0.8 \%$ & \\
\hline Grade 4 & 0 & $0.0 \%$ & & 0 & $0.0 \%$ & 0 & $0.0 \%$ & \\
\hline Altered (Gr.2-4) & 14 & $2.5 \%$ & $(1.5-4.1) \%$ & 6 & $2.0 \%$ & 8 & $3.1 \%$ & 0.427 \\
\hline To treat (Gr.3-4) & 3 & $0.5 \%$ & $(0.2-1.6) \%$ & 1 & $0.3 \%$ & 2 & $0.8 \%$ & 0.487 \\
\hline \multicolumn{9}{|c|}{ Overbite (OVB) } \\
\hline IONT-DHC Grade & \multicolumn{2}{|c|}{ Prevalence } & 95\% C.I. & \multicolumn{2}{|c|}{ Male } & \multicolumn{2}{|c|}{ Female } & $p$ \\
\hline Grade 1 & 422 & $75.5 \%$ & & 232 & $77.9 \%$ & 190 & $72.8 \%$ & \\
\hline Grade 2 & 113 & $20.2 \%$ & & 55 & $18.5 \%$ & 58 & $22.2 \%$ & \\
\hline Grade 3 & 19 & $3.4 \%$ & & 7 & $2.3 \%$ & 12 & $4.6 \%$ & \\
\hline Grade 4 & 5 & $0.9 \%$ & & 4 & $1.3 \%$ & 1 & $0.4 \%$ & \\
\hline Altered (Gr.2-4) & 137 & $24.5 \%$ & $(21.1-28.3) \%$ & 66 & $22.1 \%$ & 71 & $27.2 \%$ & 0.166 \\
\hline To treat (Gr.3-4) & 24 & $4.3 \%$ & $(2.9-6.3) \%$ & 11 & $3.7 \%$ & 13 & $5.0 \%$ & 0.453 \\
\hline \multicolumn{9}{|c|}{ Openbite (OPB) } \\
\hline IONT-DHC Grade & \multicolumn{2}{|c|}{ Prevalence } & $95 \%$ C.I. & \multicolumn{2}{|c|}{ Male } & \multicolumn{2}{|c|}{ Female } & $p$ \\
\hline Grade 1 & 495 & $88.6 \%$ & & 269 & $90.3 \%$ & 226 & $86.6 \%$ & \\
\hline Grade 2 & 32 & $5.7 \%$ & & 16 & $5.4 \%$ & 16 & $6.1 \%$ & \\
\hline Grade 3 & 23 & $4.1 \%$ & & 9 & $3.0 \%$ & 14 & $5.4 \%$ & \\
\hline Grade 4 & 9 & $1.6 \%$ & & 4 & $1.3 \%$ & 5 & $1.9 \%$ & \\
\hline Altered (Gr.2-4) & 64 & $11.4 \%$ & $(9.1-14.3) \%$ & 29 & $9.7 \%$ & 35 & $13.4 \%$ & 0.173 \\
\hline To treat (Gr.3-4) & 32 & $5.7 \%$ & $(4.1-7.9) \%$ & 13 & $4.4 \%$ & 19 & $7.3 \%$ & 0.139 \\
\hline \multicolumn{9}{|c|}{ Crossbite (CRB) } \\
\hline IONT-DHC Grade & \multicolumn{2}{|c|}{ Prevalence } & 95\% C.I. & \multicolumn{2}{|c|}{ Male } & \multicolumn{2}{|c|}{ Female } & $p$ \\
\hline Absent & 510 & $91.2 \%$ & & 270 & $90.6 \%$ & 240 & $92.0 \%$ & \\
\hline Present & 49 & $8.8 \%$ & & 28 & $9.4 \%$ & 21 & $8.0 \%$ & \\
\hline Monolateral & 35 & $6.3 \%$ & & 19 & $6.4 \%$ & 16 & $6.1 \%$ & \\
\hline Bilateral & 14 & $2.5 \%$ & & 9 & $3.0 \%$ & 5 & $1.9 \%$ & \\
\hline To treat & 49 & $8.8 \%$ & $(6.6-11.4) \%$ & 28 & $9.4 \%$ & 21 & $8.0 \%$ & 0.573 \\
\hline & & & all need for trea & & & & & \\
\hline IONT-DHC Grade & & & 95\% C.I. & & & & & $p$ \\
\hline Grade 1 & 285 & $51.0 \%$ & & 163 & $54.7 \%$ & 122 & $46.7 \%$ & \\
\hline Grade 2 & 166 & $29.7 \%$ & & 82 & $27.5 \%$ & 84 & $32.2 \%$ & \\
\hline Grade 3 & 46 & $8.2 \%$ & & 18 & $6.0 \%$ & 28 & $10.7 \%$ & \\
\hline Grade 4 & 61 & $10.9 \%$ & & 34 & $11.4 \%$ & 27 & $10.3 \%$ & \\
\hline Grade 5 & 1 & $0.2 \%$ & & 1 & $0.3 \%$ & 0 & $0.0 \%$ & \\
\hline Altered (Gr.2-5) & 274 & $49.0 \%$ & $(44.9-53.1) \%$ & 135 & $45.3 \%$ & 139 & $53.3 \%$ & 0.061 \\
\hline To treat (Gr.3-5) & 108 & $19.3 \%$ & $(16.2-22.8) \%$ & 53 & $17.8 \%$ & 55 & $21.1 \%$ & 0.326 \\
\hline
\end{tabular}

tive orthodontic prevention program should therefore include preschool children in order to intervene before malocclusions stabilize or worsen at a later age. The results obtained from this study point out that pediatricians must know and be aware about dental health in order to detect the principal and more frequent pro- blems and send the pediatric patients to orthodontists and pediatric dentists $(33,34)$. Lack of knowledge and awareness on information, health education and health promotion can potentially increase the oral health risk status of children as stated by international and national Oral Health guidelines $(35,36)$. 


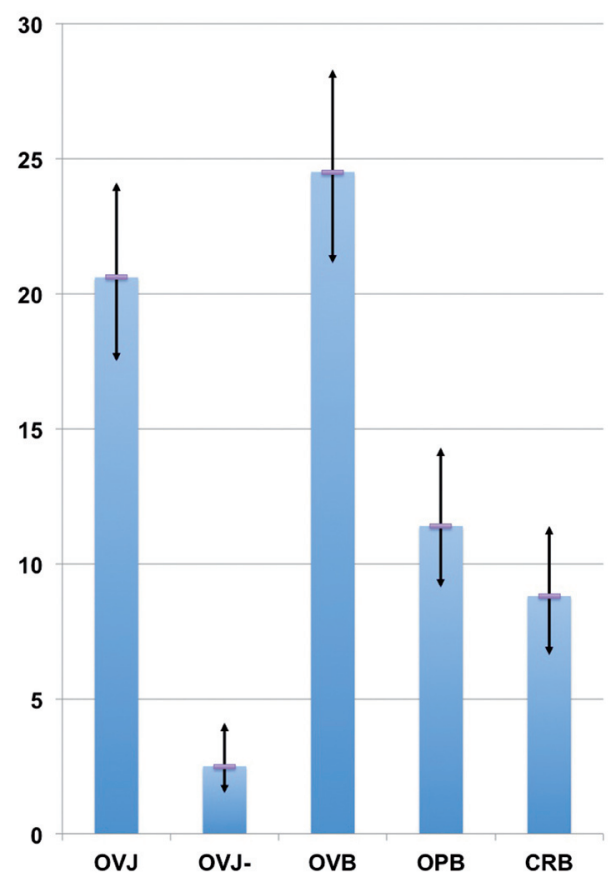

Fig. 1: Prevalence of altered occlusal parameters for overjet (OVJ), reverse overjet (OVJ-), overbite $(\mathrm{OVB})$, openbite (OPB), and crossbite (CRB) in our sample. Vertical bars indicate the $95 \%$ C.I.

\section{References}

1. Akbari M, Lankarani KB, Honarvar B, Tabrizi R, Mirhadi H, Moosazadeh M. Prevalence of malocclusion among Iranian children: A systematic review and meta-analysis. Dent Res J (Isfahan). 2016;13:387-95. 2. Hanna A, Chaaya M, Moukarzel C, El Asmar K, Jaffa M, Ghafari JG. Malocclusion in elementary school children in Beirut: severity and related social/behavioral factors. Int J Dent. 2015;2015:351231.

3. Luzzi V, Fabbrizi M, Coloni C, Mastrantoni C, Mirra C, Bossù M, et al. Experience of dental caries and its effects on early dental occlusion: a descriptive study. Ann Stomatol (Roma) 2011; 2:13-8.

4. Carta G, Cagetti MG, Sale S, Congiu G, Strohmenger L, Oleari F, et al. Italian Experimental Group on Oral Health. Oral health inequalities in Italian schoolchildren - a cross-sectional evaluation. Community Dent Health. 2014;31:123-8.

5. Greinger RM. Orthodontic treatment priority index. Am J Orthod Dentofacial Orthop. 1968;54:543-44.

6. Salzmann JA. Handicapping malocclusion assessment to establish treatment priority. Am J Orthod Dentofacial Orthop. 1968;54:749-65.

7. Summers CJ. The occlusal index: A system for identifying and scoring occlusal disorders. Am J Orthod Dentofacial Orthop. 1971;59: $552-67$.

8. Brook PH, Shaw WC. The development of an index of orthodontic treatment priority. Eur J Orthod. 1989;11:309-20.

9. Shaw WC, Richmond S, O'Brien KD, Brook P, Stephens CD. Quality control in orthodontics: indices of treatment need and treatment standards. Br Dent J. 1991;170:107-12.

10. Auconi P, Luzzi V, Ierardo G, Polimeni A. Quando è veramente utile un trattamento ortodontico? Medico e Bambino. 2006; 25:87-94.

11. Krooks L, Pirttiniemi P, Kanavakis G, Lähdesmäki R. Prevalence of malocclusion traits and orthodontic treatment in a Finnish adult population. Acta Odontol Scand. 2016;74:362-7.

12. Kasparaviciene K, Sidlauskas A, Zasciurinskiene E, Vasiliauskas A, Juodzbalys G, Sidlauskas M, et al. The prevalence of malocclusion and oral habits among 5-7-year-old children. Med Sci Monit. 2014;20:2036-2042.

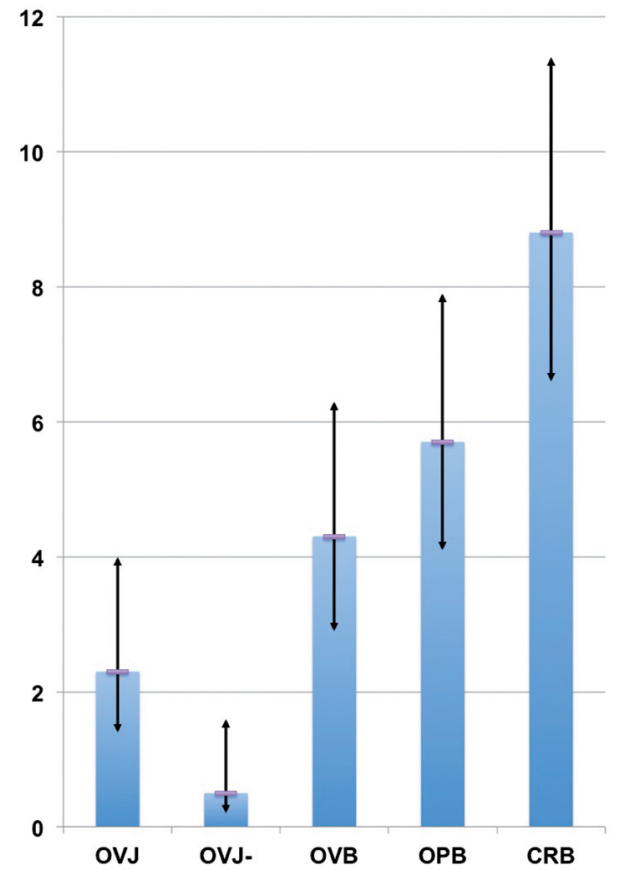

Fig. 2: Prevalence of occlusal anomalies with need for orthodontic treatment for overjet (OVJ), reverse overjet (OVJ-), overbite (OVB), openbite (OPB), and crossbite (CRB) in our sample. Vertical bars indicate the $95 \%$ C.I.

13. Luzzi V, Guaragna M, Ierardo G, Saccucci M, Consoli G, Vestri $\mathrm{AR}$, et al. Malocclusions and non-nutritive sucking habits: a preliminary study. Prog Orthod. 2011;12:114-8.

14. Puertes-Fernández N, Montiel-Company JM, Almerich-Silla JM, Manzanera D. Orthodontic treatment need in a 12-year-old population in the Western Sahara. Eur J Orthod. 2011;33:377-80.

15. Almerich-Silla JM, Montiel-Company JM, Bellot-Arcís C, Puertes-Fernández N. Cross-sectional study of malocclusion in Spanish children. Med Oral Patol Oral Cir Bucal. 2014;19:e15-9.

16. Trottini M, Bossù M, Corridore D, Ierardo G, Luzzi V, Saccucci $\mathrm{M}$, et al. Assessing risk factors for dental caries: a statistical modeling approach. Caries Res. 2015;49:226-35.

17. Johansson M, Follin ME. Evaluation of the Dental Health Component, of the Index of Orthodontic Treatment Need, by Swedish orthodontists. Eur J Orthod. 2009;31:184-8.

18. Luzzi V, Ierardo G, Ladniak B, Manzini P, Polimeni A. L'intercettamento precoce delle deviazioni mandibolari funzionali in dentatura decidua mediante l'utilizzo del dispositivo Nite Guide: Case Report. Mondo Ortodontico. 2003;3.

19. Gungor K, Taner L, Kaygisiz E. Prevalence of posterior crossbite for orthodontic treatment timing. J Clin Pediatr Dent. 2016;40:422-4. 20. Luzzi V, Ierardo G, Viscogliosi A, Fabbrizi M, Consoli G, Vozza I, et al. Allergic rhinitis as a possible risk factor for malocclusion: a casecontrol study in children. Int J Paediatr Dent. 2013;23:274-8.

21. Nobile CGA, Pavia M, Fortunato L, Angelillo IF. Prevalence and factors related to malocclusion and orthodontic treatment need in children and adolescents in Italy. Eur J Public Health. 2007;17:637-41.

22. Perillo L, Masucci C, Ferro F, Apicella D, Baccetti T. Prevalence of orthodontic treatment need in southern Italian schoolchildren. Eur J Orthod. 2010;32:49-53.

23. Souames M, Bassigny F, Zenati N, Riordan PJ, Boy-Lefevre ML. Orthodontic treatment need in French schoolchildren: an epidemiological study using the Index of Orthodontic Treatment Need. Eur J Orthod. 2006;28:605-9.

24. Manzanera D, Montiel-Company JM, Almerich-Silla JM, Gandía 
JL. Diagnostic agreement in the assessment of orthodontic treatment need using the Dental Aesthetic Index and the Index of Orthodontic Treatment Need. Eur J Orthod. 2010;32:193-8.

25. Burden DJ, Holmes A. The need for orthodontic treatment in the child population of the United Kingdom. Eur J Orthod. 1994;16:395-9.

26. Manzanera D, Ortiz LA, Gandía JL, Cibrián R, Adobes-Martín M. Indice de Necesidad de Tratamiento Ortodóncico (IOTN) en escolares de 10 a 12 años. Rev Esp Ortod. 2004;34:209-17.

27. Tausche E, Luck O, Harzer W. Prevalence of malocclusions in the early mixed dentition and orthodontic treatment need. Eur J Orthod. 2004;26:237-44.

28. Chestnutt IG, Burden DJ, Steele JG, Pitts NB, Nuttall NM, Morris AJ. The orthodontic condition of children in the United Kingdom, 2003. Br Dent J. 2006;200:609-12.

29. Mtaya M, Astrom AN, Brudvik P. Malocclusion, psycho-social impacts and treatment need: A cross-sectional study of Tanzanian primary school-children. BMC Oral Health. 2008;8:14.

30. Mtaya M, Brudvik P, Astrøm AN. Prevalence of malocclusion and its relationship with socio-demographic factors, dental caries, and oral hygiene in 12- to 14-year-old Tanzanian schoolchildren. Eur J Orthod. 2009;31:467-76.

31. Uçüncü N, Ertugay E. The use of the Index of Orthodontic Treatment need (IOTN) in a school population and referred population. J Orthod. 2001;28:45-52.

32. Abu Alhaija ES, Al-Khateeb SN, Al-Nimri KS. Prevalence of malocclusion in 13-15 year-old North Jordanian school children. Community Dent Health. 2005;22:266-71.

33. Badri P, Saltaji H, Flores-Mir C, Amin M. Factors affecting children's adherence to regular dental attendance: a systematic review. J Am Dent Assoc. 2014;145:817-28.

34. Brickhouse TH, Unkel JH, Kancitis I, Best AM, Davis RD. Infant oral health care: a survey of general dentists, pediatric dentists, and pediatricians in Virginia. Pediatr Dent. 2008;30:147-53.

35. American Academy on Pediatric Dentistry; American Academy of Pediatrics. Policy on early childhood caries (ECC): classifications, consequences, and preventive strategies. Pediatr Dent. 2008-2009;30(7 Suppl):40-3.

36. National guidelines for the promotion of oral health and prevention of oral disease in evolutive age- update 2013. Available from: www. salute.gov.it/imgs/C_17_pubblicazioni_2073_allegato.pdf.

\section{Bullet Points}

Why this paper is important for paediatric dentists

- Epidemiological data on malocclusions are relevant to public health programs aimed at orthodontic prevention.

- This study evaluates the prevalence of several malocclusions in a sample of children in the 2-9 age range from a province in Southern Italy using the IOTN-DHC index.

- Results show that orthodontic prevention at an early age can help reducing the need for more complex orthodontic treatments at later stages of the development.

Acknowledgments

The authors declare no potential conflicts of interest with respect to the authorship and/or publication of this article.

\section{Author Contributions}

V.L., G.I., A.P. and M.B. conceived the ideas; D.C., G.D.C., and G.D.G. collected the data; V.L., G.I., D.C., E.L., and G.G.C. analysed the data; and V.L., I.V. and E.L. led the writing. 